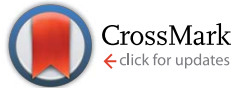

Cite this: Chem. Sci., 2017, 8, 2973

\title{
Sequential water molecule binding enthalpies for aqueous nanodrops containing a mono-, di- or trivalent ion and between 20 and 500 water molecules $\dagger$
}

\begin{abstract}
Sven Heiles, + Richard J. Cooper, Matthew J. DiTucci and Evan R. Williams*
Sequential water molecule binding enthalpies, $\Delta H_{n, n-1}$, are important for a detailed understanding of competitive interactions between ions, water and solute molecules, and how these interactions affect physical properties of ion-containing nanodrops that are important in aerosol chemistry. Water molecule binding enthalpies have been measured for small clusters of many different ions, but these values for ion-containing nanodrops containing more than 20 water molecules are scarce. Here, $\Delta H_{n, n-1}$ values are deduced from high-precision ultraviolet photodissociation (UVPD) measurements as a function of ion identity, charge state and cluster size between 20-500 water molecules and for ions with $+1,+2$ and +3 charges. The $\Delta H_{n, n-1}$ values are obtained from the number of water molecules lost upon photoexcitation at a known wavelength, and modeling of the release of energy into the translational, rotational and vibrational motions of the products. The $\Delta H_{n, n-1}$ values range from 36.82 to $50.21 \mathrm{~kJ}$ $\mathrm{mol}^{-1}$. For clusters containing more than $\sim 250$ water molecules, the binding enthalpies are between the bulk heat of vaporization $\left(44.8 \mathrm{~kJ} \mathrm{~mol}^{-1}\right)$ and the sublimation enthalpy of bulk ice $\left(51.0 \mathrm{~kJ} \mathrm{~mol}{ }^{-1}\right)$. These values depend on ion charge state for clusters with fewer than 150 water molecules, but there is a negligible dependence at larger size. There is a minimum in the $\Delta H_{n, n-1}$ values that depends on the cluster size and ion charge state, which can be attributed to the competing effects of ion solvation and surface energy. The experimental $\Delta H_{n, n-1}$ values can be fit to the Thomson liquid drop model (TLDM) using bulk ice parameters. By optimizing the surface tension and temperature change of the logarithmic partial pressure for the TLDM, the experimental sequential water molecule binding enthalpies can be fit with an accuracy of $\pm 3.3 \mathrm{~kJ} \mathrm{~mol}^{-1}$ over the entire range of cluster sizes.
\end{abstract}

Received 9th November 2016 Accepted 26th January 2017

DOI: $10.1039 / c 6 s c 04957 \mathrm{e}$

rsc.li/chemical-science

\section{Introduction}

The interactions between water molecules and solute ions can significantly affect the structure, dynamics and reactivity of the solute and the dynamics and the structures of the hydrogenbonding network of liquid water. Consequently, molecular level knowledge of these interactions is important to understanding

Department of Chemistry, University of California, Berkeley B42 Hildebrand Hall, Berkeley, California 94720-1460, USA. E-mail: erw@berkeley.edu; Tel: $+1-510-643-7161$

$\dagger$ Electronic supplementary information (ESI) available: Detailed description of the experimental and computational modeling methods. Isolation, BIRD and UVPD sequence for $\left[\mathrm{Ru}\left(\mathrm{NH}_{3}\right)_{6}\right]^{3+} \cdot\left(\mathrm{H}_{2} \mathrm{O}\right)_{169-171}$, nanoESI spectra for $2+$ and $3+$ ions. Detailed description of the isotope distribution simulation program. Comparison between experimental and simulated $1+, 2+$ and $3+$ ion isotope distributions. Wavelength dependence of the deduced sequential binding enthalpies. Comparison of experimental UVPD binding enthalpies to the liquid drop model at different temperatures. Complete list of binding enthalpies and average number of water molecules lost upon UVPD. See DOI: 10.1039/c6sc04957e \$ Current address: Institute of Inorganic and Analytical Chemistry, Justus Liebig University Giessen, 35392 Giessen, Germany. processes in solution and in the atmosphere, such as protein folding, molecular recognition and ion-assisted aerosol formation. ${ }^{1-8}$ For example, the protein interlokin- $1 \beta$ contains buried water molecules in the interior that are hydrogen bonded and bridge distant charged amino acid residues by the formation of hydrogen bonds. ${ }^{5}$ It is believed that these ion-water interactions are important for the folding dynamics and structure of the protein. Ions that are formed in the atmosphere are thought to be responsible for the fast nucleation of water molecules in the early stages of aerosol formation, where charged clusters grow faster and become thermodynamically stable at smaller cluster sizes than their neutral counterparts. ${ }^{7}$

One way to obtain detailed information about ion-solvent interactions is to study hydrated ions in a well-defined environment, i.e., clusters of water molecules containing a single ion. ${ }^{9-27}$ In this way, any effects of impurities or counter ions are eliminated. By investigating size selected clusters, it is possible to monitor how thermodynamic quantities, such as water molecule binding enthalpies, evolve with cluster size..$^{\mathbf{1 3 2 8 - 4 5}}$ Several methods have been used to measure the sequential 
water molecule binding energies of hydrated ions with up to 14 water molecules attached. ${ }^{28-45}$ The most commonly used approaches are high-pressure ion source mass spectrometry (HPMS), ${ }^{28-34}$ threshold collision induced dissociation (TCID) ${ }^{35-42}$ and blackbody infrared radiative dissociation (BIRD). ${ }^{\mathbf{4 3 - 4 5}}$ Singly and doubly charged hydrated ions have been studied with these methods. The results reveal that especially for the first hydration shell, the ion identity and charge state significantly influence water molecule binding enthalpies. As the result of increasing ion solvation, the influence of the sequential water binding enthalpies on the specific ion-water interactions diminishes with increasing cluster size. For example, the sequential water molecule binding enthalpies for hydrated $\mathrm{Li}^{+}$ decrease from 134 to $63 \mathrm{~kJ} \mathrm{~mol}^{-1}$ for one to six water molecules attached..$^{37}$

Ultraviolet photodissociation (UVPD) experiments have been used to deduce water molecule binding enthalpies at larger cluster sizes and these measurements can be made with high precision. The sequential water binding enthalpies for hydrated aniline, protonated proflavine, protonated tryptophan, rhodamine 590 and rhodamine 640 ions have been studied by UVPD. ${ }^{46,47}$ In these experiments, the sequential water molecule binding enthalpy is deduced from the number of water molecules that are lost from the cluster upon photoexcitation with a photon of known energy. For aniline ${ }^{+} \cdot\left(\mathrm{H}_{2} \mathrm{O}\right)_{n}$ with $n=5-20$ (where $n$ is the number of water molecules) for example, the energy removed per water molecule decreases from $74.5 \mathrm{~kJ}$ $\mathrm{mol}^{-1}$ at $n=5$ to an average value of $\sim 40.2 \mathrm{~kJ} \mathrm{~mol}^{-1}$ between $n$ $=10-20{ }^{46} \mathrm{~A}$ very similar trend but slightly higher sequential water molecule binding enthalpies were measured for hydrated doubly charged atomic ions and paraquat. ${ }^{47,48}$ These UVPD studies indicate that for larger cluster sizes, the sequential water molecule binding enthalpies are close to the bulk water vaporization enthalpy (43.1 $\mathrm{kJ} \mathrm{mol}^{-1}$ (ref. 49)) and depend only slightly on the cluster size. These results and recent velocity map imaging experiments ${ }^{50}$ are consistent with the idea that the absorbed photon energy is fully redistributed into the internal modes of the entire cluster for $n>10$, resulting in sequential water molecule evaporation, although ion fluorescence resulting in fewer water molecules that are lost can also occur. ${ }^{47,51}$

Despite the progress in obtaining thermodynamic reference data for larger hydrated ions, only limited data for sequential water binding enthalpies over a broad range of cluster sizes and for different charge states is available. These data are especially important to accurately model ion-induced water nucleation ${ }^{6,7}$ in the atmosphere and for ion nanocalorimetry. ${ }^{9-13}$ In the latter method, hydrated ions are irradiated, for example, with slow electrons that can lead to a one-electron reduction of the ion. ${ }^{9}$ The recombination energy (RE), which corresponds to the energy released due to the ion-electron recombination, leads to the evaporation of water molecules from the hydrated ion. The $\mathrm{RE}$ can be obtained from the number of water molecules that are lost by modeling of this thermochemical process for water evaporation, which is based on the sequential water molecule binding energies as well as energy that partitions into translational, rotational and vibrational modes of the departing water molecules. By extrapolating REs measured as a function of cluster size to "infinite dilution", absolute reduction potentials of metal ions can be measured and ultimately related to an absolute reduction potential of the standard hydrogen electrode (SHE) ${ }^{10,11,13}$ Due to the lack of thermochemical reference data for sequential water binding enthalpies of large ion-containing water clusters, the RE modeling currently uses values from the Thomson liquid drop model (TLDM). ${ }^{52-58}$ The TLDM combines the self-energy of solvating a charged particle in the Born solvation model with the increased energy due to the droplet surface area and the bulk vaporization energy to give sequential binding enthalpies of water molecules as a function of cluster size. Any systematic error in the TLDM will result in an error for the absolute SHE value obtained from the ion nanocalorimetry measurements, and this error increases with increasing number of water molecules that are lost as a result of ionelectron recombination.

In this work, we present an extensive study of sequential water binding enthalpies as a function of charge state $(z=+1-3)$, ion identity, and cluster size $(n=20-500)$ derived from highprecision UVPD measurements. A newly developed program is used to deduce $\Delta H_{n, n-1}$ from experimental precursor and product cluster distributions. The various ions studied for every charge state, the different types of electronic transitions ranging from atomic transitions to electronic excitations in aromatic systems to charge transfer transitions, and the diverse chemical nature of the formed atomic, organic and inorganic ions, make the herein presented binding enthalpy trends important for many chemically relevant systems. The sequential water molecule binding enthalpies show a clear dependence on the ionic charge and cluster size and depend less on ion identity. The results are compared to binding enthalpy predictions from the TLDM. A better agreement between theory and experiment is obtained for the TLDM model employing water ice parameters at $133 \mathrm{~K}$, indicating that the clusters may largely solidify under these experimental conditions.

\section{Results and discussion}

\section{Ultraviolet photodissociation of hydrated ions}

Nanoelectrospray ionization coupled to FT-ICR mass spectrometry is used to form and subsequently trap broad distributions of hydrated ions. Two example mass spectra of (Phe + $\mathrm{H}^{+}$measured using conditions optimized for either small or large cluster sizes are shown in Fig. 1a. Lower heated metal capillary temperatures and lower ion source potentials lead to the formation of larger clusters. Between 0 and $\sim 250$ water molecules are attached to one $(\mathrm{Phe}+\mathrm{H})^{+}$ion, as is the case for other singly charged ions (Scheme 1). For $2+$ and $3+$ ions, nanoESI mass spectra show hydrated di- and trivalent ions with up to $\sim 500$ and $\sim 600$ water molecules, respectively (see Fig. S2 $\dagger$ ). Lower detection efficiency at high $\mathrm{m} / \mathrm{z}$ limits the cluster sizes that we are able to observe. For divalent ions, the maximum cluster size is about four times greater than that reported previously in UVPD experiments $(n \approx 125)^{48}$ as a result of a higher field strength magnet used in these experiments.

Results of UVPD of $(\mathrm{Phe}+\mathrm{H})^{+}, \mathrm{Cu}^{2+}$ and $\left[\mathrm{Ru}\left(\mathrm{NH}_{3}\right)_{6}\right]^{3+}$ with $193.0 \pm 0.5 \mathrm{~nm}$ laser light, $250 \mathrm{~Hz}$ repetition rate and $0.5 \mathrm{~s}$ 

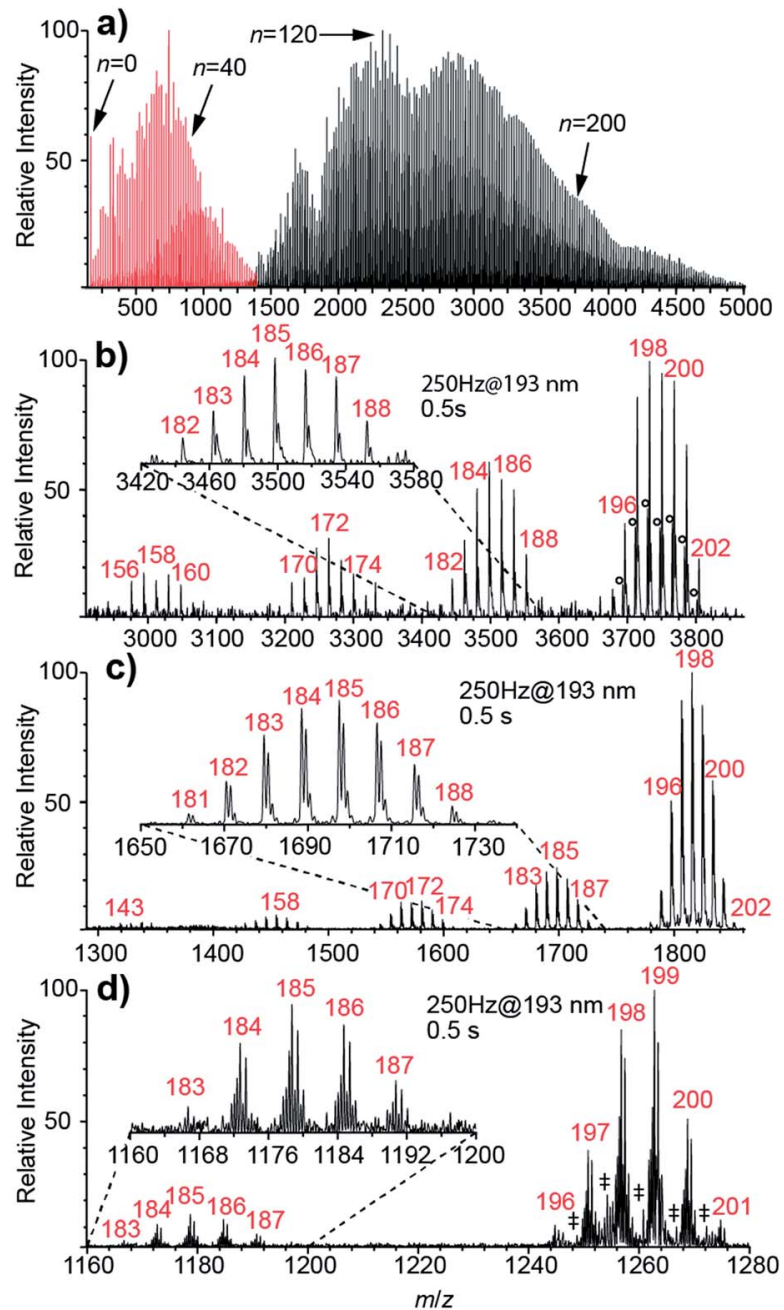

Fig. 1 (a) Overlay of two mass spectra of $(\mathrm{Phe}+\mathrm{H})^{+} \cdot\left(\mathrm{H}_{2} \mathrm{O}\right)_{n}$ optimized for small (red) and large (black) clusters. Some cluster sizes $n$ are highlighted. (b) - (d) UVPD mass spectra of (b) $(\mathrm{Phe}+\mathrm{H})^{+} \cdot\left(\mathrm{H}_{2} \mathrm{O}\right)_{198-202 \text {, }}$ (c) $\mathrm{Cu}^{2+} \cdot\left(\mathrm{H}_{2} \mathrm{O}\right)_{198-202}$ and (d) $\left[\mathrm{Ru}\left(\mathrm{NH}_{3}\right)_{6}\right]^{3+} \cdot\left(\mathrm{H}_{2} \mathrm{O}\right)_{198-202}$. After $0.5 \mathrm{~s}$ of UV radiation with $193 \mathrm{~nm}$ laser light at $250 \mathrm{~Hz}$, a loss of $\sim 13.5$ water molecules compared to the precursor cluster size is observed. The delay time of $1.0 \mathrm{~s}$ before detection was used in order to eliminate effects of any kinetic shift. The number of water molecules for the selected clusters $n$ is shown in red. (O) Unidentified chemical noise; $(\vdots)$ $\left[\mathrm{Ru}\left(\mathrm{NH}_{3}\right)\right]_{6}{ }^{2+} \cdot\left(\mathrm{H}_{2} \mathrm{O}\right)_{n}$.

irradiation time for isolated ensembles with $n=198-202$ water molecules are shown in Fig. 1b-d, respectively. In addition to the isolated precursors at $n=198-202$, new clusters with $n=$ 195-197, which are formed by BIRD, appear. The mean cluster size, $\langle n\rangle$, for the precursor distributions shown in Fig. 1bd containing $(\mathrm{Phe}+\mathrm{H})^{+}, \mathrm{Cu}^{2+}$ and $\left[\mathrm{Ru}^{2}\left(\mathrm{NH}_{3}\right)_{6}\right]^{3+}$ ions is 198.73, 198.09 and 198.60 , respectively. There are also product ion distributions at lower mass that are generated due to UVPD (Fig. 1b-d). The average cluster size of the highest mass product ion distribution that is separated from the precursor is 185.24, 184.66 and 185.17 for $(\mathrm{Phe}+\mathrm{H})^{+}, \mathrm{Cu}^{2+}$ and $\left[\mathrm{Ru}\left(\mathrm{NH}_{3}\right)_{6}\right]^{3+}$. This product ion distribution has $\langle x\rangle=13.50,13.43$ and 13.43 fewer water molecules than the corresponding precursor ion. Both the precursor and fragment distributions include contributions

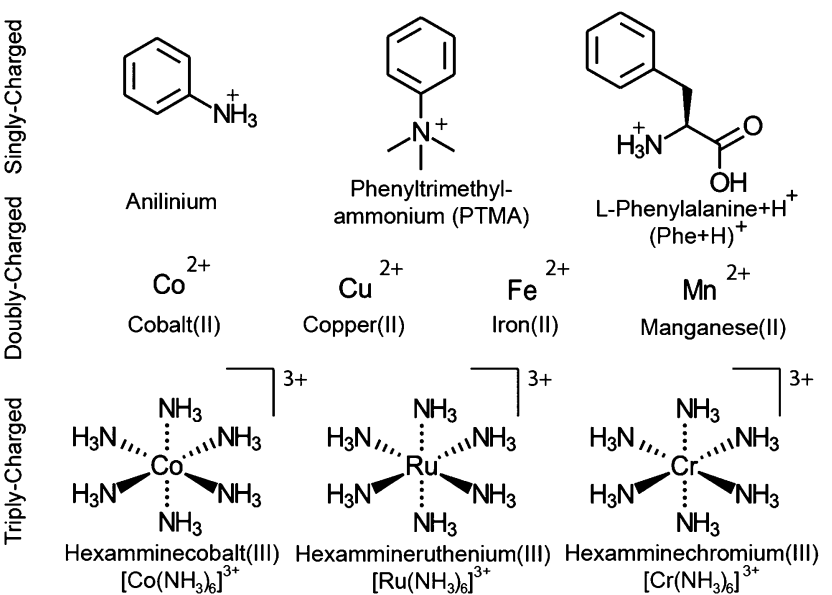

Scheme 1 Structures and abbreviations for all ions that are investigated.

from BIRD, which should effect both populations similarly for large clusters. ${ }^{48}$ The difference in the average number of water molecules for these populations should reflect just UV absorption consistent with $\langle x\rangle$ being independent of the laser irradiation time (see ESI $\dagger$ ). For $(\mathrm{Phe}+\mathrm{H})^{+} \cdot\left(\mathrm{H}_{2} \mathrm{O}\right)_{198-202}$ and $\mathrm{Cu}^{2+} \cdot\left(\mathrm{H}_{2} \mathrm{O}\right)_{198-202}$, additional product ion distributions are formed at even lower mass (Fig. $1 \mathrm{~b}$ and $\mathrm{c}$ ). For the second and third product ion distribution of $(\mathrm{Phe}+\mathrm{H})^{+}$and $\mathrm{Cu}^{2+}$ containing water clusters, an average of 26.46 (26.83) and 40.77 (40.31) water molecules are lost from the precursor ion distribution. For the UVPD mass spectra shown in Fig. $1 b$ and $c$, the consecutive product ion distributions differ by 13.4-13.5 water molecules. Thus, the absorption of one $193 \mathrm{~nm}$ UV photon by ions solvated by $\sim 200$ water molecules results in the loss of about 13.4 water molecules and the formation of product ion distributions with similar hydration state width as the precursor distribution, namely 5-7 hydration states for the precursor and 5-8 for product ion distributions. These multiple product ion distributions (Fig. 1b and c) are due to sequential UV photon absorption, i.e., one, two and three $193 \mathrm{~nm} \mathrm{UV}$ photons are absorbed sequentially to form the first, second and third product ion distribution, respectively, and not to multiphoton processes. A detailed discussion of sequential UV photon absorption on experimental UVPD results is provided in ref. 48 .

Whereas $\langle x\rangle$ for $(\mathrm{Phe}+\mathrm{H})^{+} \cdot\left(\mathrm{H}_{2} \mathrm{O}\right)_{198-202}, \mathrm{Cu}^{2+} \cdot\left(\mathrm{H}_{2} \mathrm{O}\right)_{198-202}$ and $\left[\mathrm{Ru}\left(\mathrm{NH}_{3}\right)_{6}\right]^{3+} \cdot\left(\mathrm{H}_{2} \mathrm{O}\right)_{198-202}$ do not significantly differ (Fig. 1b-d), the photofragment yield is affected by ion identity. The UVPD yields vary from $51 \%$ for $(\mathrm{Phe}+\mathrm{H})^{+} \cdot\left(\mathrm{H}_{2} \mathrm{O}\right)_{198-202}$ to $31 \%$ and $12 \%$ for $\mathrm{Cu}^{2+} \cdot\left(\mathrm{H}_{2} \mathrm{O}\right)_{198-202}$ and $\left[\mathrm{Ru}\left(\mathrm{NH}_{3}\right)_{6}\right]^{3+} \cdot\left(\mathrm{H}_{2} \mathrm{O}\right)_{198-202}$, respectively. (Phe $+\mathrm{H})^{+}$in aqueous solution has a strong absorption band between $190-210 \mathrm{~nm}$ as a result of the phenyl group. ${ }^{59}$ The UV absorption at $193 \mathrm{~nm}$ for $\left[\mathrm{Ru}\left(\mathrm{NH}_{3}\right)_{6}\right]^{3+}$ is due to a ligand-to-metal charge transfer transition. ${ }^{60}$ The molar extinction coefficient for $(\mathrm{Phe}+\mathrm{H})^{+}$in the water at $193 \mathrm{~nm}$ is about six times larger than that for $\left[\mathrm{Ru}\left(\mathrm{NH}_{3}\right)_{6}\right]^{3+},{ }^{60}$ consistent with the higher photoproduct yield for $(\mathrm{Phe}+\mathrm{H})^{+} \cdot\left(\mathrm{H}_{2} \mathrm{O}\right)_{198-202}$ compared to $\left[\mathrm{Ru}\left(\mathrm{NH}_{3}\right)_{6}\right]^{3+} \cdot\left(\mathrm{H}_{2} \mathrm{O}\right)_{198-202}$. No solution phase reference data is available for $\mathrm{Cu}^{2+}$ ions (nor other divalent 
transition metal ions) at $193 \mathrm{~nm}$ precluding a comparison to this ion. However, the photoproduct yield for $\mathrm{Cu}^{2+} \cdot\left(\mathrm{H}_{2} \mathrm{O}\right)_{198-202}$ and other divalent transition metal ions used in this study (Scheme 1) are similar to previously reported results on hydrated divalent ions with $n \leq 124 .^{48}$

\section{Relaxation following UV excitation}

An energy level diagram of absorption and possible relaxation mechanisms for a water cluster containing a single ion is shown in Fig. 2a. UV photon absorption followed by heat transfer to surrounding water molecules increases the internal energy of the cluster. If radiative emission of a visible or UV photon occurs through fluorescence, less energy is available to convert into internal modes. Thus, the number of water molecules lost
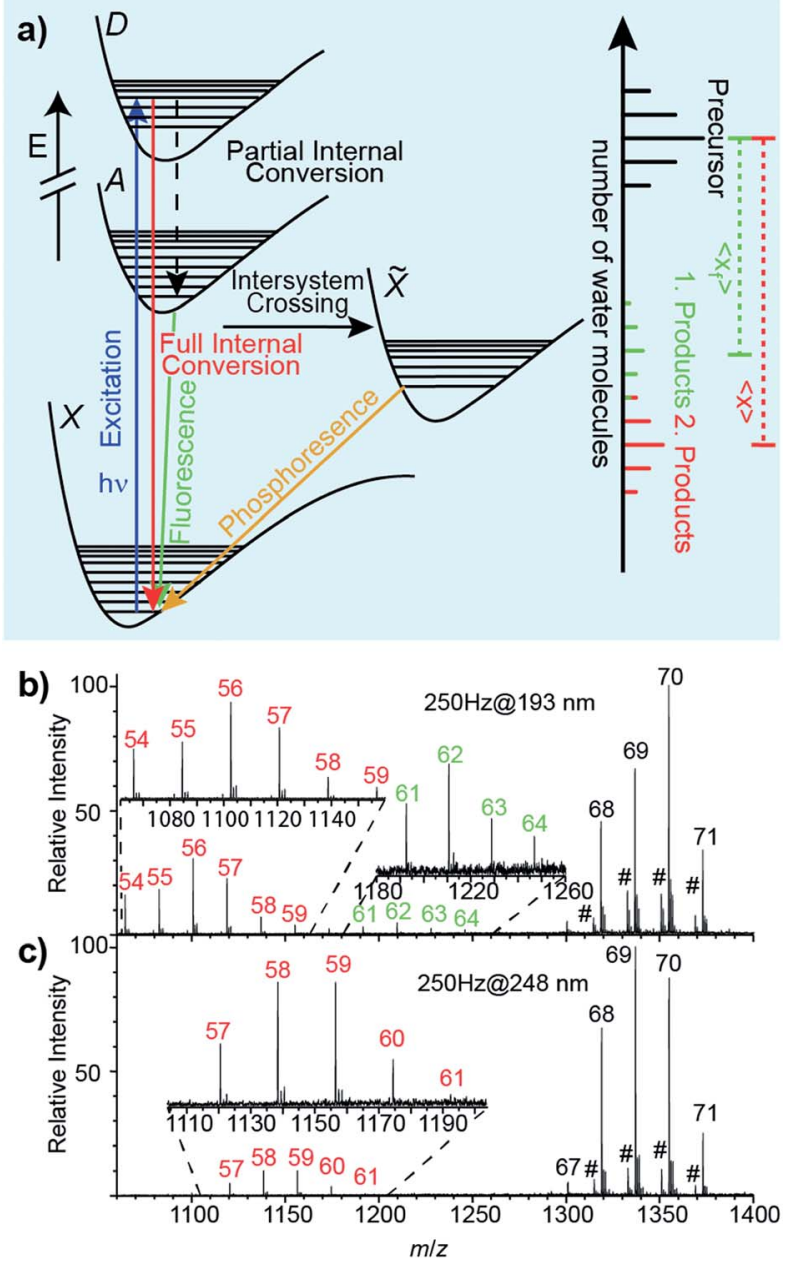

Fig. 2 (a) Jablonski diagram of photoexcitation and possible relaxation processes that can occur during UVPD experiments and example precursor and product ion distributions as a result of full internal and partial internal conversion. UVPD mass spectra of anilinium $\cdot\left(\mathrm{H}_{2} \mathrm{O}\right)_{69-71}$ at (b) $193 \mathrm{~nm}$ and (c) $248 \mathrm{~nm}$. In (b) two product distributions are observed. The distribution centered at $\langle x\rangle \approx 56$ is the result of full internal conversion. The second distribution centered at $\langle n\rangle \approx 62.5$ originates from ions that fluoresce. In (c), there is one UVPD distribution centered at $\langle n\rangle \approx 58.5$ arising from full internal conversion. (\#) Unidentified chemical noise. when the UV photon that is absorbed and is fully converted into internal modes, $\langle x\rangle$, is higher than that when partial internal conversion is followed by fluorescence, $\left\langle x_{\mathrm{f}}\right\rangle$ (Fig. 2a). Additional details of these processes are given in ref. 47 and 48.

$(\mathrm{Phe}+\mathrm{H})^{+} \cdot\left(\mathrm{H}_{2} \mathrm{O}\right)_{198-202}, \mathrm{Cu}^{2+} \cdot\left(\mathrm{H}_{2} \mathrm{O}\right)_{198-202}$ and $\left[\mathrm{Ru}\left(\mathrm{NH}_{3}\right)_{6}\right]^{3+}$. $\left(\mathrm{H}_{2} \mathrm{O}\right)_{198-202}$ lose $\sim 13.5$ water molecules upon UVPD at $193 \mathrm{~nm}$. Previously reported sequential water molecule binding energies, $E_{n, n-1}$, are $\sim 0.45 \mathrm{eV}$ per water molecule for clusters with $n=10-$ $124 .^{46,48}$ Assuming that water molecules are lost sequentially as a result of full internal conversion from an excited electronic state to the ground electronic state, the number of water molecules that are lost is estimated to be 14.2 for a $6.41 \mathrm{eV}$ photon. This is $\sim 0.7$ water molecules higher than the experimental value of $\sim 13.5$. Because this simple calculation does not take into account energy partitioned into the degrees of freedom of the water molecules that evaporated, this calculation overestimates the number of water molecules that are lost. Hence, our experimental results are consistent with water loss due to full internal conversion of the absorbed photon. Further evidence for sequential water molecule loss and full internal conversion producing the product distributions at about $\langle x\rangle=h \nu / E_{n, n-1}$ below the precursor distribution in UVPD experiments of hydrated ions comes from the wavelength-dependent UVPD measurements of anilinium $\cdot\left(\mathrm{H}_{2} \mathrm{O}\right)_{69-71}$ shown in Fig. $2 \mathrm{~b}$ and c. In the $193 \mathrm{~nm}$ UVPD experiment shown in Fig. 2b, there are two product ion distributions. The distribution corresponding to the most extensive water loss is shifted by $\langle x\rangle=13.47$ water molecules compared to the precursor ion distribution whereas the other distribution is shifted by $\left\langle x_{\mathrm{f}}\right\rangle=7.22$. The product distribution with the highest water loss is consistent with the expected loss of $\sim 13.5$ water molecules due to full internal conversion of a $193 \mathrm{~nm}$ photon, and the additional product ion distribution is due to partial internal conversion followed by fluorescence with an emitted photon wavelength of $\sim 2.80 \mathrm{eV}^{47}$ The fluorescence quantum yield, obtained from the relative ion abundances of the two product ion distributions, is 0.11 . UVPD of anilinium $\cdot\left(\mathrm{H}_{2}-\right.$ O) $)_{69-71}$ at $248 \mathrm{~nm}$ results in only a single product ion distribution corresponding to $\langle x\rangle=10.68$ (Fig. 2c). For the photon energy of $5.0 \mathrm{eV}(248 \mathrm{~nm})$, an estimated water loss of $\langle n\rangle=11.11$ is expected from full internal conversion, consistent with the experimental result. These measurements show that the fluorescent quantum yield varies significantly with excitation photon wavelength.

Because the number of water molecules lost from precursor ion distributions to product ion distributions at $\sim h \nu / E_{n, n-1}$ are consistent with a full internal conversion process and additional ion product distributions are identified for partial internal conversion/fluorescence processes, we conclude that full internal conversion and sequential water loss are the major processes leading to product ion distributions at $\langle x\rangle \approx h \nu / E_{n, n-1}$ in UVPD.

\section{Kinetic shift effect}

The time required for all of the water molecules that will ultimately evaporate from the cluster following absorption of a UV photon depends on the cluster size. The time necessary for evaporation of the water molecules increases with increasing 
cluster size owing to an increasing number of degrees of freedom over which this energy is distributed. ${ }^{61}$ The potential influence of measurement time on the product ion cluster size is a kinetic shift effect. The extent to which a kinetic shift affects these measurements is measured by varying the delay time between laser irradiation and ion detection until the maximum number of water molecules, $\left\langle x_{\max }\right\rangle$, that are lost, is observed. Results of these kinetic shift measurements as a function of cluster size, charge state and laser wavelength are shown in Fig. 3. Our results for hydrated divalent ions show an increasing kinetic shift with increasing cluster size for clusters with $n \geq$ 200 (Fig. 3a). At zero detection delay time, $\langle x\rangle$ for $\mathrm{Cu}^{2+} \cdot\left(\mathrm{H}_{2} \mathrm{O}\right)_{198-202}$, $\mathrm{Cu}^{2+} \cdot\left(\mathrm{H}_{2} \mathrm{O}\right)_{298-302}$ and $\mathrm{Co}^{2+} \cdot\left(\mathrm{H}_{2} \mathrm{O}\right)_{398-402}$ (labeled as the median of the cluster ensemble in Fig. 3) are lower than $\left\langle x_{\max }\right\rangle$ by 0.23 , 0.58 and 1.50 water molecules. For $\mathrm{Cu}^{2+} \cdot\left(\mathrm{H}_{2} \mathrm{O}\right)_{198-202}$, $\mathrm{Cu}^{2+} \cdot\left(\mathrm{H}_{2} \mathrm{O}\right)_{298-302}$ and $\mathrm{Co}^{2+} \cdot\left(\mathrm{H}_{2} \mathrm{O}\right)_{398-402}$, a delay time between photoexcitation and ion detection of $250 \mathrm{~ms}, 500 \mathrm{~ms}$ and 1000 ms are required so that $\langle x\rangle$ approaches $\left\langle x_{\max }\right\rangle$ to within 0.05 water molecules. The kinetic shift does not depend significantly on laser wavelength within this range of photon energies (Fig. 3a). At zero detection delay time, $\mathrm{Cu}^{2+} \cdot\left(\mathrm{H}_{2} \mathrm{O}\right)_{198-202}$ at 193 $\mathrm{nm}$ and $\mathrm{Fe}^{2+} \cdot\left(\mathrm{H}_{2} \mathrm{O}\right)_{218-222}$ at $248 \mathrm{~nm}$ lose 0.23 and 0.39 water molecules less than $\left\langle x_{\max }\right\rangle$ and both approach $\left\langle x_{\max }\right\rangle$ at about $250 \mathrm{~ms}$. The independence of the kinetic shift on laser wavelength is consistent with the time necessary for the water evaporation process to occur being mainly limited by the last water molecule that is lost from the cluster, which depends primarily on cluster size (degrees of freedom) and not on the initial energy deposited. The bigger difference at zero detection delay for the iron compared to the copper containing water cluster is consistent with the slightly larger cluster size of the former. The charge state dependence of the kinetic shift is investigated for $\mathrm{Cu}^{2+} \cdot\left(\mathrm{H}_{2} \mathrm{O}\right)_{298-302}$ and $\left[\mathrm{Ru}\left(\mathrm{NH}_{3}\right)_{6}\right]^{3+}$. $\left(\mathrm{H}_{2} \mathrm{O}\right)_{298-302}$ at $193 \mathrm{~nm}$ (Fig. 3b). All data points for different delay times differ by less than 0.09 water molecules for the two clusters indicating that the charge state does not significantly

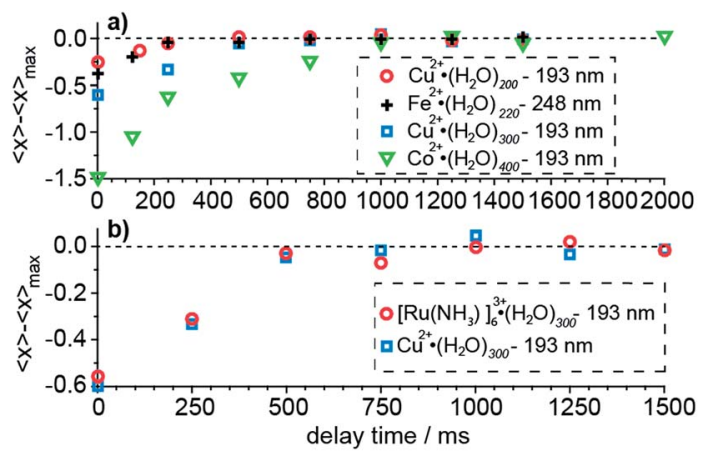

Fig. 3 The dependence of the average number of water molecules lost, $\langle x\rangle$, minus the maximum number of water molecules lost, $\left\langle x_{\max }\right\rangle$, as a function of the delay time between photoexcitation and ion detection (the kinetic shift). $\langle x\rangle$ for the largest delay time was set to $\left\langle x_{\max }\right\rangle$ as indicated by the dashed line. The median of the selected cluster ensemble is used to label the clusters. (a) Kinetic shift as a function of cluster size and wavelength. (b) Kinetic shift as a function of charge state for $\left[\mathrm{Ru}\left(\mathrm{NH}_{3}\right)_{6}\right]^{3+} \cdot\left(\mathrm{H}_{2} \mathrm{O}\right)_{300}$ and $\mathrm{Cu}^{2+} \cdot\left(\mathrm{H}_{2} \mathrm{O}\right)_{300}$. contribute to the kinetic shift effect. We conclude that the kinetic shift increases with increasing cluster size but not notably with excitation wavelength and charge state. A detection delay time after laser irradiation of $500 \mathrm{~ms}, 1000 \mathrm{~ms}$ and 1500 ms for $n<100,100 \leq n \leq 300$ and $n>300$ in our UVPD measurements, respectively, eliminates effects of the kinetic shift on the $\langle x\rangle$ and $\Delta H_{n, n-1}$ values obtained from these measurements.

\section{Effects of cluster size, ion charge and ion identity}

The effects of cluster size, ion charge and ion identity on the number of water molecules lost from different hydrated ions upon $193 \mathrm{~nm}$ and $248 \mathrm{~nm}$ photon absorption were measured as a function of cluster size and these data are shown in Fig. 4. The number of water molecules lost following photoabsorption depends on each of these factors to differing extents. For example, the number of water molecules lost upon $193 \mathrm{~nm}$ UVPD increases from a minimal value of $10.74 \pm 0.03$ for $\left[\mathrm{Ru}\left(\mathrm{NH}_{3}\right)_{6}\right]^{3+}$ with a median of 30 water molecules attached to a maximum of 14.01, 13.67 and 13.44 for mono-, di- and trivalent ions, which occurs at median cluster sizes of 70, 110 and 210 , respectively. Beyond the maxima, the number of water molecules that are lost decreases monotonically with cluster size. Similar changes in $\langle x\rangle$ with cluster size also occur for 248 $\mathrm{nm}$ UVPD. With $248 \mathrm{~nm}$ photons, $\langle x\rangle$ is about three water molecules less than that with $193 \mathrm{~nm}$ photons, but the qualitative dependence of $\langle x\rangle$ with median cluster size follows the same trends as for the $193 \mathrm{~nm}$ data (Fig. 4).

In addition to cluster size, the charge state of the hydrated ion affects the average number of water molecules that are lost (Fig. 4). For clusters of the same median size, $\langle x\rangle$ for monovalent ions is bigger than that for divalent ions which is bigger than that for trivalent ions up to a cluster size $\sim 150$. This is consistent with the TLDM model that predicts this charge-dependent

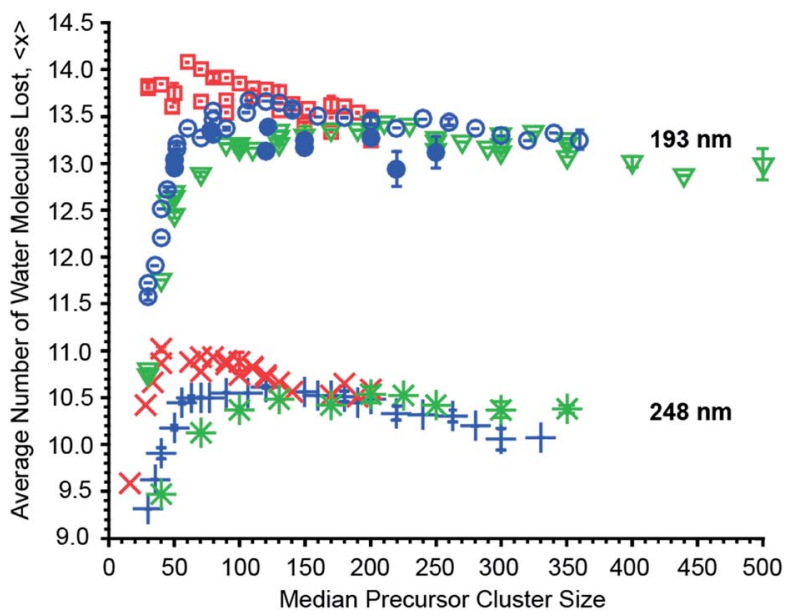

Fig. 4 Average number of water molecules lost by hydrated PTMA, $(\text { Phe }+\mathrm{H})^{+}$, anilinium ( $\square$ ); $\mathrm{Cu}^{2+}, \mathrm{Co}^{2+}(0) ; \mathrm{Fe}^{2+}, \mathrm{Mn}^{2+}(0) ;\left[\mathrm{Co}\left(\mathrm{NH}_{3}\right)_{6}\right]^{3+}$, $\left[\mathrm{Cr}\left(\mathrm{NH}_{3}\right)_{6}\right]^{3+},\left[\mathrm{Ru}\left(\mathrm{NH}_{3}\right)_{6}\right]^{3+}(\nabla)$ ions upon $193 \mathrm{~nm}$ photon absorption and $(\text { Phe }+\mathrm{H})^{+}$, anilinium $(X) ; \mathrm{Fe}^{2+}(+) ;\left[\mathrm{Ru}^{2}\left(\mathrm{NH}_{3}\right)_{6}\right]^{3+}(*)$ upon $248 \mathrm{~nm}$ photon absorption as a function of median precursor cluster size. Error bars indicate the standard deviation of triplicate measurements. 
ordering of $E_{n, n-1} \cdot{ }^{52}$ The differences in the number of water molecules that are lost deceases significantly for clusters with more than $\sim 150$ water molecules (Fig. 4 ). This indicates a vanishing influence of the charge state on the binding energies of water molecules to the large clusters.

The identity of the ion of a given charge state and at the same cluster size has only a small effect on the number of water molecules lost (Fig. 4). For example, $\left[\mathrm{Ru}\left(\mathrm{NH}_{3}\right)_{6}\right]^{3+}$ and $\left[\mathrm{Co}\left(\mathrm{NH}_{3}\right)_{6}\right]^{3+}$ with 100 water molecules or $\left[\mathrm{Ru}\left(\mathrm{NH}_{3}\right)_{6}\right]^{3+}$ and $\left[\mathrm{Cr}\left(\mathrm{NH}_{3}\right)_{6}\right]^{3+}$ with 350 water molecules lose $13.21 \pm 0.03$ and $13.16 \pm 0.03$ or 13.21 and 13.26 water molecules at $193 \mathrm{~nm}$ excitation wavelength. Similarly, $\langle x\rangle$ differs only by 0.02 for 248 $\mathrm{nm}$ UVPD of $(\mathrm{Phe}+\mathrm{H})^{+}$and anilinium with 120 water molecules attached. Although the number of water molecules lost following photoabsorption is minimally affected by ion identity for the majority of the ions investigated, $\langle x\rangle$ at $193 \mathrm{~nm}$ for hydrated $\mathrm{Mn}^{2+}$ and $\mathrm{Fe}^{2+}$ ions differs significantly from that for $\mathrm{Cu}^{2+}$ and $\mathrm{Co}^{2+}$ at precursor sizes with $n>130$. At a precursor ensemble size of $220,\langle x\rangle$ is $13.38 \pm 0.04$ and $12.94 \pm 0.19$ for $\mathrm{Cu}^{2+}$ and $\mathrm{Fe}^{2+}$, respectively. More water molecules can be lost from a cluster either as a result of lower water molecule binding energies or competition between water molecule loss and internal energy conversion. If internal conversion is not instantaneous, ions are not heated to as high of an effective temperature compared to when internal conversion is instantaneous because water molecules that evaporate during internal conversion take away energy. Thus, less energy partitions into translational, rotational and vibration energy of evaporated water molecules. There is evidence for a long-lived excited state for $\mathrm{Cu}^{2+}$ in smaller nanodrops for which competition between water loss and internal conversion could be relevant, but this effect should be negligible for the larger clusters investigated here owing to a slower water molecule evaporation rate. ${ }^{\mathbf{1 0 , 6 2}}$ Thus, the different number of water molecules lost for $\mathrm{Cu}^{2+} / \mathrm{Co}^{2+}$ compared to $\mathrm{Fe}^{2+} / \mathrm{Mn}^{2+}$ likely reflect a difference in water molecule binding enthalpy. A comparison between the divalent ions at $248 \mathrm{~nm}$ is not possible because UVPD products are only observed for $\mathrm{Fe}^{2+}$. However, the decrease of $\langle x\rangle$ for hydrated $\mathrm{Fe}^{2+}$ at $248 \mathrm{~nm}$ with increasing cluster size, even below $\langle x\rangle$ for trivalent ions, is also consistent with an increasing binding enthalpy with increasing cluster size (Fig. 4). This is unexpected because the influence of ion identity should decrease with increasing cluster size. ${ }^{47,48}$ A possible explanation for this effect is an ion specific water patterning effect, so that $\mathrm{Fe}^{2+} / \mathrm{Mn}^{2+}$ containing water clusters form water clusters differing in shape or water phase from $\mathrm{Cu}^{2+} / \mathrm{Co}^{2+} \cdot\left(\mathrm{H}_{2} \mathrm{O}\right)_{n}$. Evidence for the influence of ions on the water phase in large water clusters comes from a recent study that showed that $\mathrm{La}^{3+}$ ions can affect the onset of crystallinity in clusters as large as 375 water molecules. ${ }^{63}$

\section{Effective cluster temperatures and kinetic energy release}

After absorption of one UV photon and full internal conversion back to the electronic ground state of an ion, the effective temperature of the cluster increases from its initial effective temperature of $\sim 133 \mathrm{~K}$ established by the interaction of the ions with the blackbody radiation field inside the ion cell prior to photoexcitation. Absorption of a photon shifts the initial internal energy distribution of the cluster by a value corresponding to the energy of the photon. The extent of this effective temperature increase depends on the cluster size and the energy of the absorbed photon and is modeled as described in the ESI. $\uparrow$ This effect is illustrated for two different $\mathrm{Cu}^{2+}$ cluster sizes (Fig. 5). Upon absorption of a $6.41 \mathrm{eV}$ photon and internal conversion, the initial effective temperature of $\mathrm{Cu}^{2+} \cdot\left(\mathrm{H}_{2} \mathrm{O}\right)_{40}$ and $\mathrm{Cu}^{2+} \cdot\left(\mathrm{H}_{2} \mathrm{O}\right)_{400}$ prior to any water molecule loss increases to $\sim 550 \mathrm{~K}$ and $\sim 190 \mathrm{~K}$, respectively. Both clusters cool back down to $\sim 130 \mathrm{~K}$ after 13 water molecules are lost. The higher initial effective temperature of $\mathrm{Cu}^{2+} \cdot\left(\mathrm{H}_{2} \mathrm{O}\right)_{40}$ compared to $\mathrm{Cu}^{2+} \cdot\left(\mathrm{H}_{2} \mathrm{O}\right)_{400}$ is due to the lower number of degrees of freedom of the smaller cluster. The energy partitioned into the degrees of freedom for the sequentially evaporated water molecules depends on the effective cluster temperature at which each water molecule is lost (ESI eqn (3) $\dagger$ ). Consequently, the lower effective temperature for $\mathrm{Cu}^{2+} \cdot\left(\mathrm{H}_{2} \mathrm{O}\right)_{400}$ than that for $\mathrm{Cu}^{2+} \cdot\left(\mathrm{H}_{2} \mathrm{O}\right)_{40}$ results in less $\left\langle E_{\mathrm{VRT}}\right\rangle$ (see Fig. $5 ;\left\langle E_{\mathrm{VRT}}\right\rangle=8.16$ and $3.68 \mathrm{~kJ} \mathrm{~mol}^{-1}$ for $\mathrm{Cu}^{2+} \cdot\left(\mathrm{H}_{2} \mathrm{O}\right)_{40}$ and $\mathrm{Cu}^{2+} \cdot\left(\mathrm{H}_{2} \mathrm{O}\right)_{400}$, respectively). The sequential water molecule binding energies for $\mathrm{Cu}^{2+} \cdot\left(\mathrm{H}_{2} \mathrm{O}\right)_{40}$ and $\mathrm{Cu}^{2+} \cdot\left(\mathrm{H}_{2} \mathrm{O}\right)_{400}$ obtained by modeling the water molecule loss are $39.37 \mathrm{~kJ} \mathrm{~mol}^{-1}$ and $43.85 \mathrm{~kJ} \mathrm{~mol}^{-1}$, respectively. The relative energy contribution from the total energy release of 8.16 and $3.68 \mathrm{~kJ} \mathrm{~mol}^{-1}$ for $\mathrm{Cu}^{2+} \cdot\left(\mathrm{H}_{2} \mathrm{O}\right)_{40}$ and $\mathrm{Cu}^{2+} \cdot\left(\mathrm{H}_{2} \mathrm{O}\right)_{400}$ to the deposited energy of $6.41 \mathrm{eV}$ is $17 \%$ and $8 \%$, respectively, and decreases with increasing cluster size. Thus, any systematic error in the computed binding energies introduced by using this energy release model decreases with cluster size. For mono-, di- and trivalent clusters with up to 350 water molecules, the difference between calculated binding energies obtained from $248 \mathrm{~nm}$ and $193 \mathrm{~nm}$ UVPD experiments are shown in Fig. S6. $\dagger$ The mean difference between $248 \mathrm{~nm}$ and $193 \mathrm{~nm}$ binding energies is $0.4 \pm 0.6 \mathrm{~kJ} \mathrm{~mol}^{-1}$. The average difference of $0.4 \mathrm{~kJ} \mathrm{~mol}^{-1}$ for $248 \mathrm{~nm}$ compared to $193 \mathrm{~nm}$

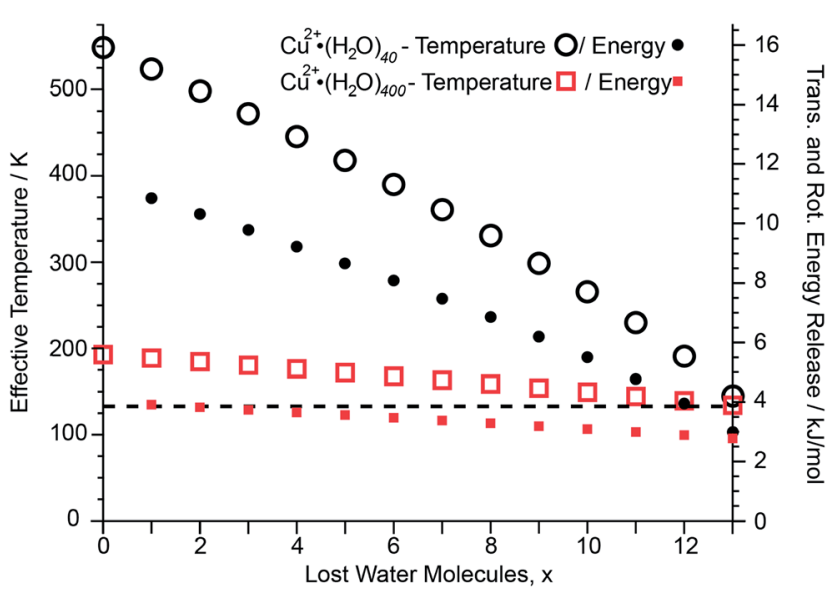

Fig. 5 Effective cluster temperature (open symbols) and translational/ rotational energy (filled symbols) release for $\mathrm{Cu}^{2+} \cdot\left(\mathrm{H}_{2} \mathrm{O}\right)_{40}$ (black) and $\mathrm{Cu}^{2+} \cdot\left(\mathrm{H}_{2} \mathrm{O}\right)_{400}(\mathrm{red})$ as a function of water molecules that are lost from the cluster, $\langle x\rangle$, upon absorption of a $193 \mathrm{~nm}$ photon. The dashed black line indicates the experimental temperature of $133 \mathrm{~K}$. 
binding energies indicates that the model may slightly overestimate the kinetic energy release, but this difference is well within the uncertainty of our measurements. This indicates that the kinetic energy release model introduces no significant systematic error for the calculation of average sequential binding enthalpies from UVPD experiments.

\section{Average water molecule binding enthalpies and the liquid drop model}

The average sequential binding enthalpies for mono-, di- and trivalent ions obtained from these UVPD experiments, along with previously published data for clusters with fewer than 15 water molecules ${ }^{32-45}$ as a function of $\langle n\rangle-\langle x\rangle / 2$ are shown in Fig. 6 . The uncertainty in size and enthalpy of the $\Delta H_{n, n-1}$ values are $\pm\langle x\rangle / 2$ $= \pm 5.5-7.5$ water molecules and $\pm 0.4-1.2 \mathrm{~kJ} \mathrm{~mol}^{-1}$, respectively. The average binding enthalpies for clusters with 20 to 500 attached water molecules decrease for the smallest investigated clusters with increasing cluster size until a minimum in $\Delta H_{n, n-1}$ is reached (Fig. 6). Namely, $\Delta H_{n, n-1}$ for mono-, di- and trivalent ions decrease from $40.75 \mathrm{~kJ} \mathrm{~mol}^{-1}, 45.06 \mathrm{~kJ} \mathrm{~mol}^{-1}$ and $50.3 \pm$ $0.16 \mathrm{~kJ} \mathrm{~mol}^{-1}$ for the investigated cluster with the least number of water attached to a minimum of $37.09 \pm 0.04 \mathrm{~kJ} \mathrm{~mol}^{-1}, 40.83 \pm$ $0.03 \mathrm{~kJ} \mathrm{~mol}^{-1}$ and $43.01 \mathrm{~kJ} \mathrm{~mol}^{-1}$ that is located around $\langle n\rangle-\langle x\rangle /$ $2 \approx 15,45$ and 75 , respectively. Beyond the minimum, the binding enthalpies increase with increasing cluster size reaching $44.32 \pm 0.20 \mathrm{~kJ} \mathrm{~mol}^{-1}, 46.17 \pm 0.58 \mathrm{~kJ} \mathrm{~mol}^{-1}$ and $47.22 \pm 0.81 \mathrm{~kJ}$ $\mathrm{mol}^{-1}$ for $(\mathrm{Phe}+\mathrm{H})^{+} \cdot\left(\mathrm{H}_{2} \mathrm{O}\right)_{198-202}, \mathrm{Cu}^{2+} \cdot\left(\mathrm{H}_{2} \mathrm{O}\right)_{358-362}$ and $\left[\mathrm{Co}\left(\mathrm{NH}_{3}\right)_{6}\right]^{3+} \cdot\left(\mathrm{H}_{2} \mathrm{O}\right)_{498-502}$, respectively. The average water

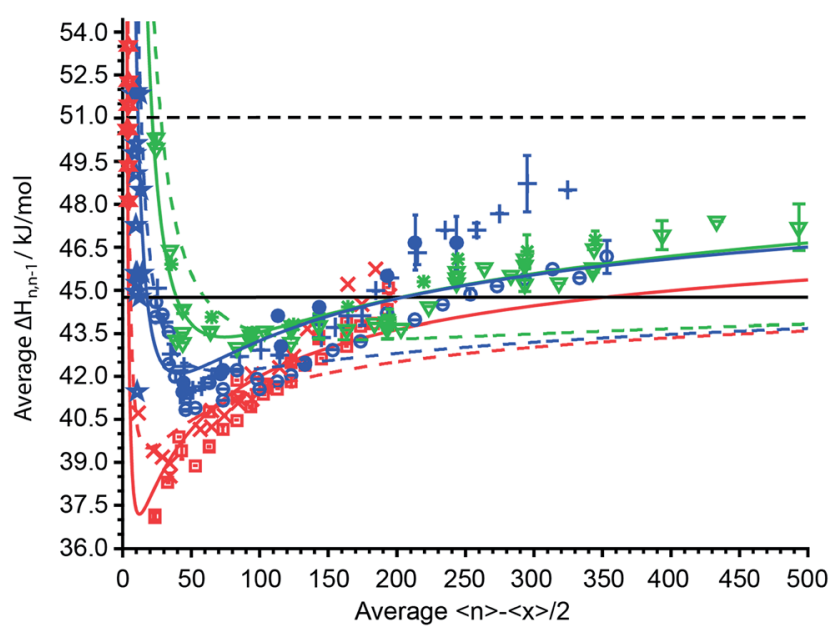

Fig. 6 The average sequential water molecule binding enthalpy, $\Delta H_{n, n-1}$, in $\mathrm{kJ} \mathrm{mol}^{-1}$ deduced from UVPD measurements for hydrated PTMA, (Phe $+\mathrm{H})^{+}$, anilinium (口) $\mathrm{Cu}^{2+}, \mathrm{Co}^{2+}(0) ; \mathrm{Fe}^{2+}, \mathrm{Mn}^{2+}(0)$; $\left[\mathrm{Co}\left(\mathrm{NH}_{3}\right)_{6}\right]^{3+},\left[\mathrm{Cr}\left(\mathrm{NH}_{3}\right)_{6}\right]^{3+},\left[\mathrm{Ru}\left(\mathrm{NH}_{3}\right)_{6}\right]^{3+}(\nabla)$ ions upon $193 \mathrm{~nm}$ photon absorption and $(\mathrm{Phe}+\mathrm{H})^{+}$, anilinium $(X) ; \mathrm{Fe}^{2+}(+) ;\left[\mathrm{Ru}\left(\mathrm{NH}_{3}\right)_{6}\right]^{3+}(*)$ upon $248 \mathrm{~nm}$ photon absorption as a function of $\langle n\rangle-\langle x\rangle / 2$. The sublimation enthalpy $\Delta H_{\text {sub }}=51.0 \mathrm{~kJ} \mathrm{~mol}{ }^{-1}$ of bulk water ice at $133 \mathrm{~K}$ and the vaporization enthalpy $\Delta H_{\text {vap }}=44.8 \mathrm{~kJ} \mathrm{~mol}^{-1}$ of bulk water at $273 \mathrm{~K}$ are depicted as dashed and solid black horizontal lines, respectively. The TLDM at $133 \mathrm{~K}$ and the fitted TLDM are shown as dashed and solid red, blue and green lines for mono-, di-, and trivalent ions, respectively. Literature binding enthalpies for clusters with $\langle n\rangle-\langle x\rangle / 2 \leq 12$ monovalent $(*)$ and divalent $(*)$ ions are included in the figure. ${ }^{32-45}$ molecule binding enthalpies of hydrated $\mathrm{Cu}^{2+} / \mathrm{Co}^{2+}$ ions approach a value of $\sim 46.0 \mathrm{~kJ} \mathrm{~mol}^{-1}$ at large cluster size, whereas that for hydrated $\mathrm{Fe}^{2+} / \mathrm{Mn}^{2+}$ ions is $48.53 \mathrm{~kJ} \mathrm{~mol}^{-1}$ (Fig. 6). For $\langle n\rangle$ $-\langle x\rangle / 2=40-125$, the average binding enthalpy of divalent ions is $42.3 \pm 0.8 \mathrm{~kJ} \mathrm{~mol}^{-1}$, consistent with a previously reported value of $43.1 \pm 0.4 \mathrm{~kJ} \mathrm{~mol}^{-1}$ ions with this same charge state and within this same cluster size range. ${ }^{48}$ Although $\Delta H_{n, n-1}$ depends on the charge state for small clusters, the average water molecule binding enthalpies converge towards the same values within $\pm 0.63 \mathrm{~kJ} \mathrm{~mol}^{-1}$ for clusters with $\sim 150$ or more water molecules. The only exceptions are $\Delta H_{n, n-1}$ values for $\mathrm{Fe}^{2+} / \mathrm{Mn}^{2+}$ ions that are up to $2.5 \mathrm{~kJ} \mathrm{~mol}^{-1}$ above the average binding enthalpies of all other ions. This shows that high accuracy UVPD measurements are able to detect specific ion effects on $\Delta H_{n, n-1}$ up to cluster sizes of $\sim 300$. The binding enthalpies for all charge states are below the sublimation enthalpy of bulk ice at $133 \mathrm{~K}\left(\Delta H_{\text {sub }}=51.0 \mathrm{~kJ}\right.$ $\left.\mathrm{mol}^{-1}\right)$ but exceed the enthalpy of vaporization at $273 \mathrm{~K}\left(\Delta H_{\mathrm{vap}}=\right.$ $44.8 \mathrm{~kJ} \mathrm{~mol}^{-1}$ ) for large cluster size. ${ }^{49}$

Also shown in Fig. 6 (dashed colored lines) are the average binding enthalpies calculated with the TLDM (see ESI $\dagger$ ) using $133 \mathrm{~K}$ bulk ice parameters (Table 1 ). The mean deviation of the TLDM at $133 \mathrm{~K}$ with ice parameters for mono-, di- and trivalent ions is lower than the mean deviations (root-mean-squaredeviation; RMSD) of the TLDM at $273 \mathrm{~K}, 298 \mathrm{~K}$ and $313 \mathrm{~K}$ using liquid water parameters (see ESI $\dagger$ ). Namely, the RMSD for monovalent ions is $4.69 \mathrm{~kJ} \mathrm{~mol}^{-1}, 2.47 \mathrm{~kJ} \mathrm{~mol}^{-1}, 2.01 \mathrm{~kJ} \mathrm{~mol}^{-1}$ and $1.38 \mathrm{~kJ} \mathrm{~mol}^{-1}$ at $313 \mathrm{~K}, 298 \mathrm{~K}, 273 \mathrm{~K}$ and $133 \mathrm{~K}$, respectively. The use of ice parameters for the TLDM calculations is consistent with recent results, which indicate that large clusters are "ice-like" at low temperature. ${ }^{63-66}$ It is still debated at what cluster size the thermodynamic concept of phase is applicable to nanodrops and it has been shown that spectroscopic features for amorphous and crystalline ice can coexist for clusters with up to 550 water molecules, ${ }^{63}$ hence, we use the phrase "ice-like" in what follows as a synonym for the presence of amorphous or crystalline ice phases.

Although the TLDM using $133 \mathrm{~K}$ bulk ice parameters provides binding enthalpies that are more similar to the experimental values for small clusters compared to those using liquid water parameters, the model does not accurately account for the increase of $\Delta H_{n, n-1}$ with cluster size above $\langle n\rangle-\langle x\rangle / 2 \approx$ 175. In order to improve the agreement between values from the

Table 1 Bulk water properties at $133 \mathrm{~K}^{a}$

\begin{tabular}{ll}
\hline Parameters & $133 \mathrm{~K}$ \\
\hline$M / \mathrm{g} \mathrm{mol}^{-1}$ & 18.015 \\
$\rho / \mathrm{kg} \mathrm{m}^{-1}$ & $931.7^{b}$ \\
$\partial \rho / \partial T / \mathrm{kg} \mathrm{m}^{-3} \mathrm{~K}^{-1}$ & $-0.065^{b}$ \\
$\varepsilon$ & $197.4^{c}$ \\
$\partial \varepsilon / \partial T / \mathrm{K}^{-1}$ & $-1.5300^{c}$ \\
$\gamma / \mathrm{mN} \mathrm{m}^{-1}$ & $109^{d}$ \\
$\partial \gamma / \partial T / \mathrm{mN} \mathrm{m}^{-1} \mathrm{~K}^{-1}$ & $-0.1407^{e}$ \\
$\ln \left(p / p_{0}\right)$ & $-28.6471^{b}$ \\
$\partial \ln \left(p / p_{0}\right) / \partial T / \mathrm{K}^{-1}$ & $0.3185^{b}$ \\
${ }^{a}$ ref. $52 .{ }^{b}$ ref. $49 .^{c}$ ref. $69 .{ }^{d}$ ref. 70. & \\
&
\end{tabular}
value only marginally effect the results. 
TLDM and the experiment at large cluster size changing the least number of parameters in the model, a sensitivity analysis was performed. The surface energy, $\gamma$, and the change of the logarithmic partial pressure with temperature, $\partial \ln \left(p / p_{0}\right) / \partial T\left(p_{0}\right.$ is the standard pressure), have the biggest effect on the TLDM at large cluster size. For mono-, di- and trivalent ions, these two parameters were optimized and the resulting fits are shown in Fig. 6 (solid colored lines). The corresponding charge-dependent parameters are shown in Table 2. The RMSD values improve from $1.25 \mathrm{~kJ} \mathrm{~mol}^{-1}, 1.92 \mathrm{~kJ} \mathrm{~mol}^{-1}$ and $2.05 \mathrm{~kJ} \mathrm{~mol}^{-1}$ for the $133 \mathrm{~K}$ TLDM to $0.92 \mathrm{~kJ} \mathrm{~mol}^{-1}, 1.17 \mathrm{~kJ} \mathrm{~mol}^{-1}$ and $0.67 \mathrm{~kJ}$ $\mathrm{mol}^{-1}$ for the corresponding fits for mono-, di- and trivalent ions, respectively. The surface energy and $\partial \ln \left(p / p_{0}\right) / \partial T$ increase for all charge states compared to bulk $133 \mathrm{~K}$ parameters and the extent of the increase depends on charge. For example, the surface tension for divalent ions is $215 \mathrm{mN} \mathrm{m}^{-1}$, which is nearly double the corresponding bulk value. Excluding the $\mathrm{Fe}^{2+} / \mathrm{Mn}^{2+}$ data for the fit of the TLDM for divalent ions, i.e., only using $\Delta H_{n, n-1}$ values for $\mathrm{Cu}^{2+}$ and $\mathrm{Co}^{2+}$ (Table 2 values in parentheses), results in a value of $180 \mathrm{mN} \mathrm{m}^{-1}$ for $\gamma$ (Fig. S10†). The higher value of $\gamma$ compared to bulk parameters of pure water ice and the increase in this value with charge state is consistent with the influence of ions on surface energy in electrolyte solutions. ${ }^{67}$ In bulk solutions, the relative surface energy increase of dilute electrolyte solutions compared to pure water is between $0-15 \%$ for salts such as $\mathrm{K}_{2} \mathrm{SO}_{4}$ and up to $100-160 \%$ for $\mathrm{LaCl}_{3}$ or $\mathrm{K}_{4}\left[\mathrm{Fe}(\mathrm{CN})_{6}\right]{ }^{67}$ Even though these clusters contain only one isolated cation and up to 500 water molecules, solution data provide support for the use of a higher surface energy in the TLDM that should be charge dependent. This indicates that hydrated ions can influence the properties of water, such as surface energy, in clusters containing up to 500 water molecules. The higher $\partial \ln \left(p / p_{0}\right) / \partial T$ for clusters compared to bulk water is in qualitative agreement with the Kelvin equation, which predicts an increase of droplet partial pressure compared to bulk water. ${ }^{68}$

Although optimization of the $133 \mathrm{~K}$ TLDM results in an improved fit to the experimental data, it is difficult to interpret the physical relevance of the extracted parameters. The values of $\gamma$ and $\partial \ln \left(p / p_{0}\right) / \partial T$ are averaged over all cluster sizes between $n$ $=20-500$ so there is no explicit size dependence of these parameters. The TLDM also has difficulties in accurately reproducing $\Delta H_{n, n-1}$ for small hydrated ions because specific

Table 2 Optimized surface energy, $\gamma$, and $\partial \ln \left(p / p_{0}\right) / \partial T$ in the TLDM for $133 \mathrm{~K}$ using $\Delta H_{n, n-1}$ values for clusters with 20-500 water molecules and compared to bulk parameters. The RMSD between of experiment and theory is given in $\mathrm{kJ} \mathrm{mol}{ }^{-1}$. For divalent ions the results in parentheses indicate the fit without $\mathrm{Fe}^{2+} / \mathrm{Mn}^{2+}$ ions

\begin{tabular}{llll}
\hline Charge & $\gamma / \mathrm{mN} \mathrm{m}^{-1}$ & $\partial \ln \left(p / p_{0}\right) / \partial T / 10^{-2} \mathrm{~K}^{-1}$ & $\mathrm{RMSD} / \mathrm{kJ} \mathrm{mol}^{-1}$ \\
\hline $1+$ & $182 \pm 23$ & $34.3 \pm 0.7$ & 0.92 \\
$2+$ & $215 \pm 26(180 \pm 27)$ & $35.5 \pm 0.8(34.1 \pm 0.8)$ & $1.17(0.84)$ \\
$3+$ & $269 \pm 17$ & $36.4 \pm 0.5$ & 0.67 \\
Bulk & $109^{a}$ & $31.8^{b}$ & - \\
${ }^{a}$ ref. $69 .{ }^{b}$ ref. 49. & &
\end{tabular}

bonding in the first and second solvation shells is not taken into account by the TLDM. ${ }^{52}$ Finally, large and hydrophobic ions like $(\mathrm{Phe}+\mathrm{H})^{+}$or PTMA may not be fully solvated or the nanodrop may not be spherical at small cluster sizes. Despite these factors, the close agreement with experimental data justifies the use of the modified TLDM. Additionally, the relatively close correspondence of the optimized parameters to the bulk ice parameters at $133 \mathrm{~K}$, considering the discussed uncertainties, is consistent with isolated ions in larger nanodrops as "ice-like" particles in the gas phase.

\section{Conclusions}

High-resolution UVPD results as a function of charge state and cluster size for a diverse set of ion-containing nanodrops containing up to 500 water molecules, which include data for trivalent ions for the first time, are presented. Average sequential water molecule binding energies are obtained with $\pm 0.8 \mathrm{~kJ}$ $\mathrm{mol}^{-1}$ precision. These data have a minimum in $\Delta H_{n, n-1}$ at around 75, 45 and $\sim 15$ water molecules for $3+, 2+$ and $1+$, respectively. This minimum in the binding enthalpies is predicted by the TLDM and stems from the counteracting energetic contributions of the surface and solvation energies. Therefore, these results are consistent with all qualitative predictions of the TLDM. However, the precision of the UVPD results reveal that the unmodified TLDM does not adequately fit the experimental data and the closest agreement between experimental and TLDM values for $\Delta H_{n, n-1}$ is achieved using $133 \mathrm{~K}$ parameters. Indications for a water-ice phase transition for water clusters with 60-79 water molecules at $133 \pm 6 \mathrm{~K}$ and for a phase transition to crystalline ice for $\mathrm{La}^{3+} \cdot\left(\mathrm{H}_{2} \mathrm{O}\right)_{375}$ at $133 \mathrm{~K}$ have been reported previously. ${ }^{63-66}$ Therefore, our interpretation of the increased average water molecule binding enthalpies within a modified $133 \mathrm{~K}$ TLDM is consistent with these findings. With bulk ice parameters and optimizing $\gamma$ and $\partial \ln \left(p / p_{0}\right) / \partial T$, the experimental values can be reproduced with accuracies of $\pm 0.8 \mathrm{~kJ} \mathrm{~mol}^{-1}$ between $n=20-500$ water molecules. Even though the TLDM is a very simplified model of these complex systems, it does a remarkable job in qualitatively explaining the experimental results. The physical significance of the optimized $\gamma$ and $\partial \ln \left(p / p_{0}\right) / \partial T$ values is difficult to evaluate, but the agreement between experimental $\Delta H_{n, n-1}$ values and the TLDM with modified ice parameters indicates that the larger clusters are "ice-like" under our experimental conditions. These binding enthalpies can serve as valuable reference values for simulations of ion-induced nucleation. Additionally, values will further improve the accuracy and precision of absolute reduction potential values deduced from ion nanocalorimetry measurements of ions in nanodrops.

\section{Acknowledgements}

This material is based upon work supported by the National Science Foundation Division of Chemistry under grant number CHE 1609866, and from the German National Academy of Sciences Leopoldina (LPDS 2012-15) for a postdoctoral schol$\operatorname{arship}(\mathrm{SH})$. 


\section{References}

1 K. A. Dill, T. M. Truskett, V. Vlachy and B. Hribar-Lee, Annu. Rev. Biophys. Biomol. Struct., 2005, 34, 173-199.

2 Y. Levy and J. N. Onuchic, Annu. Rev. Biophys. Biomol. Struct., 2006, 35, 389-415.

3 T. Vajda and A. Perczel, J. Pept. Sci., 2014, 20, 747-759.

4 C. J. Cramer and D. G. Truhlar, Chem. Rev., 1999, 99, 21612200.

5 J. C. Covalt, M. Roy and P. A. Jennings, J. Mol. Biol., 2001, 307, 657-669.

6 R. Zhang, A. Khalizov, L. Wang, M. Hu and W. Xu, Chem. Rev., 2012, 112, 1957-2011.

7 F. Yu, Atmos. Chem. Phys., 2006, 6, 5193-5211.

8 M. Meot-Ner Mautner, Chem. Rev., 2012, 112, PR22-103.

9 J. T. O'Brien, J. S. Prell, A. I. S. Holm and E. R. Williams, J. Am. Soc. Mass Spectrom., 2008, 19, 772-779.

10 W. A. Donald, R. D. Leib, J. T. O'Brien, M. F. Bush and E. R. Williams, J. Am. Chem. Soc., 2008, 130, 3371-3381.

11 W. A. Donald, R. D. Leib, M. Demireva, J. T. O'Brien, J. S. Prell and E. R. Williams, J. Am. Chem. Soc., 2009, 131, 13328-13337.

12 W. A. Donald, M. Demireva, R. D. Leib, M. J. Aiken and E. R. Williams, J. Am. Chem. Soc., 2010, 132, 4633-4640.

13 W. A. Donald and E. R. Williams, Pure Appl. Chem., 2011, 83, 2129-2151.

14 M. F. Bush, R. J. Saykally and E. R. Williams, ChemPhysChem, 2007, 8, 2245-2253.

15 M. F. Bush, R. J. Saykally and E. R. Williams, J. Am. Chem. Soc., 2008, 130, 15482-15489.

16 J. T. O'Brien and E. R. Williams, J. Phys. Chem. A, 2011, 115, 14612-14619.

17 R. J. Cooper, S. Heiles, M. J. DiTucci and E. R. Williams, J. Phys. Chem. A, 2014, 118, 5657-5666.

18 W. H. Robertson, E. G. Diken, E. A. Price, J.-W. Shin and M. A. Johnson, Science, 2003, 299, 1367-1372.

19 W. H. Robertson and M. A. Johnson, Annu. Rev. Phys. Chem., 2003, 54, 173-213.

20 E. Garand, T. Wende, D. J. Goebbert, R. Bergmann, G. Meijer, D. M. Neumark and K. R. Asmis, J. Am. Chem. Soc., 2010, 132, 849-856.

21 A. E. Bragg, J. R. R. Verlet, A. Kammrath, O. Cheshnovsky and D. M. Neumark, J. Am. Chem. Soc., 2005, 127, 1528315295.

22 J. R. R. Verlet, A. E. Bragg, A. Kammrath, O. Cheshnovsky and D. M. Neumark, Science, 2005, 307, 93-96.

23 A. E. Bragg, J. R. R. Verlet, A. Kammrath, O. Cheshnovsky and D. M. Neumark, Science, 2004, 306, 669-671.

24 L. Ma, K. Majer, F. Chirot and B. von Issendorff, J. Chem. Phys., 2009, 131, 144303.

25 J. B. Fenn, M. Mann, C. K. Meng, S. F. Wong and C. M. Whitehouse, Mass Spectrom. Rev., 1990, 9, 37-70.

26 M. J. DiTucci, S. Heiles and E. R. Williams, J. Am. Chem. Soc., 2015, 137, 1650-1657.

27 M. F. Bush, R. J. Saykally and E. R. Williams, Int. J. Mass Spectrom., 2006, 253, 256-262.
28 D. Liu, T. Wyttenbach, P. E. Barran and M. T. Bowers, J. Am. Chem. Soc., 2003, 125, 8458-8464.

29 D. Liu, T. Wyttenbach, C. J. Carpenter and M. T. Bowers, J. Am. Chem. Soc., 2004, 126, 3261-3270.

30 D. Liu, T. Wyttenbach and M. T. Bowers, J. Am. Chem. Soc., 2006, 128, 15155-15163.

31 B. Gao, T. Wyttenbach and M. T. Bowers, J. Am. Chem. Soc., 2009, 131, 4695-4701.

32 A. T. Blades, P. Jayaweera, M. G. Ikonomou and P. Kebarle, J. Chem. Phys., 1990, 92, 5900.

33 M. Peschke, A. T. Blades and P. Kebarle, J. Phys. Chem. A, 1998, 102, 9978-9985.

34 A. T. Blades and P. Kebarle, J. Phys. Chem. A, 2005, 109, 82938298.

35 N. F. Dalleska, K. Honma, L. S. Sunderlin and P. B. Armentrout, J. Am. Chem. Soc., 1994, 116, 3519-3528.

36 N. F. Dalleska, B. L. Tjelta and P. B. Armentrout, J. Phys. Chem., 1994, 98, 4191-4195.

37 M. T. Rodgers and P. B. Armentrout, J. Phys. Chem. A, 1997, 101, 1238-1249.

38 D. R. Carl, R. M. Moision and P. B. Armentrout, Int. J. Mass Spectrom., 2007, 265, 308-325.

39 T. E. Cooper, D. R. Carl and P. B. Armentrout, J. Phys. Chem. A, 2009, 113, 13727-13741.

40 T. E. Cooper and P. B. Armentrout, Chem. Phys. Lett., 2010, 486, 1-6.

41 D. R. Carl, B. K. Chatterjee and P. B. Armentrout, J. Chem. Phys., 2010, 132, 044303.

42 D. R. Carl and P. B. Armentrout, ChemPhysChem, 2013, 14, 681-697.

43 S. E. Rodriguez-Cruz, R. A. Jockusch and E. R. Williams, J. Am. Chem. Soc., 1998, 120, 5842-5843.

44 S. E. Rodriguez-Cruz, R. A. Jockusch and E. R. Williams, J. Am. Chem. Soc., 1999, 121, 8898-8906.

45 R. L. Wong, K. Paech and E. R. Williams, Int. J. Mass Spectrom., 2004, 232, 59-66.

46 S. H. Nam, H. S. Park, M. A. Lee, N. R. Cheong, J. K. Song and S. M. Park, J. Chem. Phys., 2007, 126, 224302.

47 W. A. Donald, R. D. Leib, M. Demireva and E. R. Williams, J. Am. Chem. Soc., 2011, 133, 18940-18949.

48 W. A. Donald, R. D. Leib, M. Demireva, B. Negru, D. M. Neumark and E. R. Williams, J. Phys. Chem. A, 2011, 115, 2-12.

49 D. R. Lide, CRC Handbook of Chemistry and Physics. A readyreference book of chemical and physical data, CRC, Taylor \& Francis, Boca Raton, Fla., London, 91st edn, 2010.

50 H. Abdoul-Carime, F. Berthias, L. Feketeova, M. Marciante, F. Calvo, V. Forquet, H. Chermette, B. Farizon, M. Farizon and T. D. Mark, Angew. Chem., Int. Ed., 2015, 54, 14685-14689.

51 W. A. Donald, R. D. Leib, M. Demireva, B. Negru, D. M. Neumark and E. R. Williams, J. Am. Chem. Soc., 2010, 132, 6904-6905.

52 W. A. Donald and E. R. Williams, J. Phys. Chem. A, 2008, 112, 3515-3522.

53 A. W. Castleman, J. Chem. Phys., 1972, 57, 3629.

54 N. Lee, R. G. Keesee and A. W. Castleman Jr, J. Colloid Interface Sci., 1980, 75, 555-565. 
55 A. W. Castleman, P. M. Holland and R. G. Keesee, J. Chem. Phys., 1978, 68, 1760.

56 G. H. Peslherbe, B. M. Ladanyi and J. T. Hynes, J. Phys. Chem. A, 1999, 103, 2561-2571.

57 J. J. Thomson, Applications of Dynamics and Chemistry, Macmillan and Co., London, 1888, pp. 165-166.

$58 \mathrm{~J}$. J. Thomson, Conduction of Electricity through Gases, Macmillan and Co., London, 1888, pp. 149-150.

59 R. F. Steiner and I. Weinryb, Excited States of Proteins and Nucleic Acids, Plenum Press, New York, 1971.

60 D. Guenzburger, A. Garnier and J. Danon, Inorg. Chim. Acta, 1977, 21, 119-131.

61 R. A. Marcus, J. Chem. Phys., 1952, 20, 359-364.

62 W. A. Donald and E. R. Williams, J. Am. Soc. Mass Spectrom., 2010, 21, 615-625.
63 R. J. Cooper, M. J. DiTucci, T. M. Chang and E. R. Williams, J. Am. Chem. Soc., 2016, 138, 96-99.

64 C. Hock, M. Schmidt, R. Kuhnen, C. Bartels, L. Ma, H. Haberland and B. v. Issendorff, Phys. Rev. Lett., 2009, 103, 073401.

65 M. Schmidt and B. von Issendorff, J. Chem. Phys., 2012, 136, 164307.

66 C. C. Pradzynski, R. M. Forck, T. Zeuch, P. Slavíček and U. Buck, Science, 2012, 337, 1529-1532.

67 P. B. Petersen and R. J. Saykally, J. Am. Chem. Soc., 2005, 127, 15446-15452.

68 W. Thomson, Philos. Mag., 1871, 42, 448-452.

69 O. Wörz, J. Chem. Phys., 1969, 51, 1546.

70 W. M. Ketcham and P. V. Hobbs, Philos. Mag., 1969, 19, 1161-1173. 